\title{
Diversifying students-as-partners participants and practices
}

\author{
Editors: *Alison Cook-Sather, Education Program, Bryn Mawr College, USA, and Sarah Slates, \\ Graduate School of Social Work and Social Research, Bryn Mawr College, USA
}

Contributors: Anita Acai, Tracie Addy, Karen Arm, Nandeeta Bala, Jessica Baxter, Rachel Bond, Ming-Dao Chia, Naima Crisp, Kriti Garg, Julia Groening, Muhammad Zafar Iqbal, Madelaine-Marie Judd, Ayesha Khan, Gray Kochhar-Lindgren, Jose Ernesto Escobar Lema, Lily Leung, Marie-Theres Lewe, Lisa Marie Lewis, Rose Lewis, Yifei Liang, Tom Lowe, Isabelle Lys, Kelly Matthews, Mallika Mukherji, Jennifer O'Brien, Renee Pfeifer-Luckett, Heather Poole, Nadia Lujan Bello Rinaudo, Holly Beth Rodgers, Susanne Schmidt, Irene Semos, Alyssa C. Smith, Nicola Watchman Smith, Brooke Szucs, Vander Tavares, Donna Thompson, Preeti Vayada, Meng Zhang, Tracy Zou, and Hannah Zurcher

\section{Contact: acooksat@brynmawr.edu}

In this issue of IJSaP, we are piloting this new "Voices from the Field" section with a collection of contributions that highlight the importance of increasing diversity among students-as-partners participants and diversifying students-as-partners practices. Two IJSaP coeditors, Alison Cook-Sather (faculty co-editor) and Sarah Slates (student co-editor), assumed leadership for this pilot section. We have taken an approach to crafting it that borrows from some established practices in publishing in general and in partnership spaces in particular and that experiments with some new ones. The goal of this new section is to create a space to share a diversity of emerging ideas, opinions, and perspectives on important questions about partnership work. More specifically, we aim to support the voices of those who might not normally be represented within traditional forms of academic publishing and/or who do not have time for, or interest in, working through the peer-review process but who have something to say. We juxtapose authors' perspectives under categories that emerged from the contributions, and we present them with minimal editing, interpretation, or analysis so that the voices can speak for themselves, to one another, and with readers.

To gather the first set of contributions, we sent direct invitations to a few colleagues and posted an open invitation on the IJSaP website and on several international listservs. The call was also shared on social media (e.g., Twitter) by some members of the scholarship of teaching and learning (SoTL) community. The invitations included this prompt: Over the next 35 years, how might students-as-partners work develop in a wider variety of contexts around the world and feature a greater diversity of experiences and voices? We received 22 responses from students, 13 from academic staff/faculty, and five from professional staff/administrators for a total of 28 contributions (some single authored, some co-authored). These contributors stated that they were writing from a variety of countries and regions: Australia, Asia, Canada, 
China, Germany, Hong Kong, Papua New Guinea, Saudi Arabia, South America, Europe, the United Kingdom, and the United States.

We invited contributors to name dimensions of their identities that they wanted highlighted, and we include that list below, in contributors' own words. We acknowledge, though, that there are various voices that need to be heard and that not everyone had access to the call for contributions to this new section. We therefore see this acknowledgement as another step toward equity and inclusion, knowing that simply listing dimensions of identity does not ensure either. Dimensions of identity that contributors mentioned included: BIPOC (Black, Indigenous, People of Color); Chinese SaP (students as partners) explorer; cis-gender woman; co-op student (integrating work into study); Director, Learning Technology Development; female; first-generation student or first in family at college; immigrant; international student; low-income; Melanesian-indigenous academic; member of the LGBTIQUA+ (lesbian, gay, bisexual, transgender, intersex, queer or questioning, unspecified, and asexual) community; multilingual; PhD student; student assistant; teaching and research academic; transnational; woman of color; and working-class academic. Of the 40 contributors, 19 (47\%) stated that this was their first time publishing. We include for each contribution author's or authors' name(s), their current role and, when provided by the contributor(s), their institution, and the country in which the authors are currently studying, working, or both.

There are many cross-cutting themes and currents in the responses we received. Acknowledging that the contributions could have been grouped in numerous ways, and that several could have been included in a number of different places, we grouped them under the following four loose and often overlapping categories, some of which have subcategories. Contributors confirmed that their words were appropriately located.

- Whose voices are included and how to hear them?

- Cross-cultural communication, exploration, and interpretation

- Which voices are missing/excluded?

- Language and power

- Responsible research informed by multiple perspectives

- Institutional- and structural-level rethinking

○ Building a students-as-partners ethos

- Breaking out of rigid structures/ways of being

- Crossing disciplinary and institutional boundaries

We do not mean to suggest that these are the only generative or even obvious categories. We invite readers to think about how different points from across the contributions speak to one another and inspire us to think about how student-staff, student-faculty, and student-student partnership work might develop in a wider variety of contexts around the world and feature a greater diversity of experiences and voices over the next 3-5 years.

There are numerous ways this new section of IJSaP is striving to push beyond traditional boundaries and norms in academic publishing. First, we acknowledge both individual voices and 
collective contributions. Relatedly, students, academics, and professional staff all co-create together equally. Furthermore, anyone was welcome to submit, and the submissions we received were minimally edited and grouped in loose categories to allow a story (one of many possible stories) to unfold through juxtaposition of voices rather than through analysis. Finally, we collect the references included in different contributions at the end of the document in a single "Collective References" section. We chose to do this both so that authors' words flow from one contribution to another without the interruption of references, and also so that the collection of contributions offers its own, encompassing set of resources for further exploration. This new section is neither an article nor an edited volume in a traditional sense, and this choice to have authors' words juxtaposed and distinct from larger conversations of which they might be a part aims to highlight once again the individual and collective dimensions of this work.

Also pushing beyond traditional boundaries and norms in academic publishing, we used shared Google Docs to further dialogue between contributors and co-editors. We invited all contributors and several members of the IJSaP Editorial Board to review drafts of Voices from the Field and provide feedback. While many publishing processes include multiple exchanges, this approach was more extensive and collaborative. As co-editors, we worked to integrate all responses we received into the current version below.

\section{WHOSE VOICES ARE INCLUDED AND HOW TO HEAR THEM?}

\section{Cross-cultural communication, exploration, and interpretation}

l'd like to evoke more attention to how cross-cultural/intercultural dialogue unfolds in partnerships. In partnerships, students and staff exchange perspectives, sharing meaning and co-creating learning and teaching through ongoing dialogues. However, as an international student studying in Australia, I have experienced challenges of building dialogue with people with different languages, cultural preferences, and cultural experiences. I consider the ongoing dialogue as the foundation of genuine partnerships, and inviting participants from different cultural backgrounds into partnerships requires us to explore a new form of dialogue-intercultural dialogue. Exploring how intercultural dialogue unfolds in partnerships helps us get a better understanding of the collaborative process of culturally diverse participants. From my perspective, building cross-cultural awareness in partnerships can start with exploring the process of sharing meanings in intercultural dialogue.

-Meng Zhang, student, from China, studying in Australia

As indicated by the recent scoping review of SaP in Asian countries (Liang \& Matthews, 2020), Asian SaP practitioners mainly followed the theoretical and practical experience from Western scholarship and predominantly positioned Confucianism as a barrier and challenge of successful SaP implementation in Asian universities, also evidenced by Kaur 
(2020) in the latest issue of IJSaP. However, Asian local cultures should not be ignored as $\mathrm{SaP}$ is perceived as a context-dependent and inclusive idea. Thus, as a Chinese SaP explorer, I advocate for exploring greater understanding of how SaP is happening and being understood in Chinese universities. Rather than being limited by Western theorisations and practices, we should conceptualise SaP intersecting with the unique values and norms reflected by local educational culture and beliefs (e.g., the historical interpretation of Confucian values and Confucian education principles). Then, further, we should explore the suitable ways of SaP in Chinese universities, to contextdependently expand SaP in Chinese higher education.

-Yifei Liang, PhD student from China, The University of Queensland, Chinese SaP explorer, studying in Australia

Dialogue is critical for any knowledge-building relationship. There is a taken-for-granted knowledge system (Western knowledge) that shapes the culture of "students-aspartners." Featuring greater diversity and reaching new contexts means first acknowledging the dominant knowledge system, and then it means being open to new ways of knowing, being, and acting. Hello there. We are Irene-a female, Melanesian $\mathrm{PhD}$ student, and Kelly - a female, non-indigenous academic advisor. We have a dialogue in our student-advisor relationship that resembles what Martin Nakata (2007), who is a Torres Strait Islander, calls the concept of the "cultural interface." This is a pedagogical and pragmatic space of dialogue that allows an appreciation of the points of convergence and divergence in our different knowledge systems. Through reflexive approaches, like the cultural interface, appreciating holistic ways of knowledge, there is greater hope that partnership praxis becomes more inclusive by valuing indigenous ways of knowing.

-Irene Semos, student from Papua New Guinea, studying in Australia, and Kelly Matthews, academic/faculty, Institute for Teaching and Learning Innovation, The University of Queensland, Australia

\section{Which voices are missing/excluded?}

The voices of multilingual international students (MISs) who speak English as an additional language remain largely absent from the students-as-partners literature and scholarship. As an educator with extensive experience working with MISs in Canada, I have experienced first hand the multiple contributions MISs make to Canadian higher education and society. In the increasingly more complex context of higher education, partnership with MISs can contribute to diversifying and enhancing the approaches through which we engage with difficult questions about the world today within academe. Despite the growing and significant presence of MISs in higher education worldwide nowadays, classroom curricula continue to be designed for the domestic and native-speaker student. Students-as-partners as a framework for scholarship affords us 
the opportunity to work with and learn from MISs to produce a kind of pedagogy that is more ethical and inclusive.

- Vander Tavares, academic/faculty, York University, Canada

There is an emerging scholarship that seeks to engage with diverse voices in Students as Partners practices. For SaP theorisations and practices to be truly inclusive, they need to bring missing students' voices from non-Western backgrounds to the forefront. This matters for SaP scholarship because the absence of global voices leads to universalisation and dominance of Western ideas. It prevents SaP from "representing culturally relevant, decolonised practices" (Bindra et al., 2018, p. 11). International students from the Indian subcontinent form a large student population in knowledge economies. These students come from diverse educational experiences, some of whom may not have experienced collaborative teaching and learning in their home country. Understanding their experiences matters as their voices have so far been unrepresented. The inclusion of these voices can bring new insights into how these students perceive and receive partnership practices.

-Preeti Vayada, student from India, studying at The University of Queensland, Australia

An oft-overlooked opportunity for student partnership working sits within the higher and degree apprenticeship provision. In the UK, the Apprenticeship Reform (2017) produced a swell of university-level apprentices engaging with degree course material and assessment. These apprentices share classroom experiences with their "traditional" route peers, but their opportunity to inform curriculum and learning innovation something that symbolises the essence of student partnership working -is often scarce. So, how do we address this? Universities and colleges need to guarantee that apprentices can access the routes to influence that we have so mindfully carved out for our wider student body. Grant your apprentices access to student forums, committees, and other such spaces. Their voice will be one rich with professional experience and unique vocational insight; something we, as a sector, are aiming to instil in our graduates. Recent advancements in our remote learning capacity might provide the perfect opportunity to do this.

-Nicola Watchman Smith, professional staff, Advance HE, UK

In student-staff partnerships, how do we engage the disengaged? What are the barriers for engaging? A team of four students and two staff from Australia, Asia, South America, and Europe embarked on a journey to answer these questions to enhance accessibility and inclusion in partnership at The University of Queensland in the years ahead. What did they find? Joining the partnership community isn't easy, especially for those from diverse backgrounds. If you don't know about this opportunity, don't feel like you fit in, or have been rejected, your access to partnership is limited. The solution? You. Yes, you who are already a partnership-converted student or staff member. Ask yourself, in your 
networks, who hasn't been involved in partnership and why haven't they? Encourage and support them to overcome barriers for engaging in partnership. Don't stop with one person. Keep going. Together we can make partnership a space for everyone. - Jose Ernesto Escobar Lema, Julia Groening, Kriti Garg, Nadia Lujan Bello Rinaudo, Naima Crisp, and Mallika Mukherji, team of four student partners and two staff partners, Australia (The University of Queensland); Australia, Asia, South America and Europe (the team)

Prestigious program. Exclusive opportunity. For student leaders. These are some of the phrases used to encourage students to join SaP programs across Australia. But what if you aren't "good enough" for any of these things? What if you aren't high achieving, but you have good ideas on how you could be better supported? What if you have a borderline GPA (grade point average), but a talent for throwing social events? Does this apply to you? Are you invited? When I first encountered SaP at university, I was "average." These labels didn't apply to me, so I didn't feel I could apply. What happens when your "average" students don't believe they are good enough to apply? Do you believe that a course redesigned by all high achieving students will benefit the "average" student? Will events made by just one group appeal to others? When you write your invitations, think about who you are inviting with your language.

-Brooke Szucs, student, The University of Queensland, Australia

\section{Language and power}

I believe that meaningful Students-as-Partners ( $\mathrm{SaP}$ ) work is happening in many places around the world, but the discourse around it may not always be accessible to folks. SaP exists under many labels, or perhaps, no label at all. A careful consideration of the language of partnership is needed to make our scholarship more accessible.

Furthermore, scholarly publication is not the only way in which SaP work can meaningfully be disseminated. With the notion of SoTL as public scholarship (e.g., Chick, 2019) in mind, might greater diversity be achieved if we consider disseminating SaP work in non-traditional ways, such as art displays, blogs, film/theatre, podcasts, or social media? Finally, I wonder whether we can broaden the SaP community to include folks from spaces where SaP does not-or perhaps cannot-exist. I imagine there are many important lessons to be learned here, as well.

-Anita Acai, PhD student, McMaster University, Canada

Not just a storage room of students. So often we hear staff members saying, "I'll just get some students' opinions on this" or "I just want some students to do that." We may have even said such words ourselves in the past. However, what this type of discourse can imply is that students speak with one voice, are commodities that we can tap into and/or results in tapping the same students on the shoulder for their perspectives. 
Whilst this may not be the intention, this type of language can inhibit opportunities to engage in an ethos that is premised upon breaking down power hierarchies and a space for mutual learning. It is vital for us, as practitioners of SaP, to critically and with care think about how our words may impact or stymie our efforts to engage in partnership. -Madelaine-Marie Judd, Student Partners Adviser and student, Australia

\section{RESPONSIBLE RESEARCH INFORMED BY MULTIPLE PERSPECTIVES}

Working as a project assistant at a research center for my co-op has been an incredible experience. I've had the chance to work with well-respected researchers and get a behind-the-scenes look at what happens to put a research paper together. The project I am currently working on is to do with why business schools aren't reporting on principle seven in their sharing information on progress reports to the UN Principles of Responsible Management Education (PRME). I learned many best practices for reporting while analyzing over 100 schools' reports and documenting how they report on their sustainability initiatives. In the next few years it would be great to see students playing an even larger part in research such as being able to present findings to organizations such as the UN.

\section{-Jessica Baxter, student, Canada}

All of the undergraduates at the University of Hong Kong must fulfil their Common Core requirement (https://commoncore.hku.hk/) and Critical Zones: Gender, Cities, and WellBeing serves as a cornerstone of our transdisciplinary undergraduate research initiatives. We have recently hired three student Peer Mentors and a Research Assistant/Coach to help support these Mentors. Her major tasks are to guide students regarding research processes, to connect them with the United Nations' Sustainable Development Goals (SDG) resources, and to facilitate collaboration. Student teams will articulate the concept of "critical zones" and undertake research projects to enhance common goals around issues of gender, cities, and well-being.

- Lily Leung, Research Assistant and Student Coach for Critical Zones; Tracy Zou, Assistant Professor in the Centre for the Enhancement of Teaching \& Learning; and Gray Kochhar-Lindgren, Professor and Director of the Common Core, University of Hong Kong

Students could work as partners in research by working more closely with professors to deliver course content, such as writing lesson plans, sourcing readings and other educational material, and even delivering a lecture. Bringing students into the other side of the classrooms provides an opportunity to research and study areas of interest from a different perspective. Working as a co-op student in a research centre at the University of Victoria, one of the projects I'm working on is incorporating sustainability content in the business school's curriculum through a repository of sustainability-centred lesson plans for professors. Each lesson plan is focused around one of the 17 UN Sustainable 
Development Goals and ties into the core areas of business. As a student, it is inspiring to see what goes into each lesson, and an excellent opportunity to have a voice in what is being taught to our future leaders.

-Rachel Bond, student, University of Victoria, Canada

Engagement with research, teaching, and publication, driven by students. My example is the Field Studies in Functional Ecology course run by the Australian National University, a two-week subsidised field trip which immerses interested undergraduates - from varied social, economic, and academic backgrounds -in all steps of the research process. During the course, students identify a question from existing work, design an experiment, collaboratively collect and analyse data, and present to students, staff, and external stakeholders. Exceptional research is collated and published in books edited by student volunteers. All research is novel work of genuine interest. Students who participate in the course develop the capacity to work alongside researchers as partners while still undergraduates, and are actively encouraged to reflect on and communicate aspects of their identity as scientists. Personally, I doubted my capacity as a potential researcher until I spent two weeks doing real research on real problems with real researchers.

-Hannah Zurcher and Ming-Dao Chia, former students, Australian National University, Australia

\section{INSTITUTIONAL- AND STRUCTURAL-LEVEL RETHINKING}

\section{Building a students-as-partners ethos}

I was first introduced to the Students-as-Partners ethos when I was tasked with developing a Student Governance Framework at the University of the Sunshine Coast (USC) in late 2017. I incorporated this ethos from the ground up and partnered with over 80 students throughout the development and implementation phases. Three years later, the three-tiered model is fully established and highly regarded by the USC executive. The structure is comprised of 16 student-led groups made up of 142 diverse and fully trained Student Reps. Throughout 2020, I have had the pleasure of seeing the plan come to life, and each time I see the student voice amplified and manifested in action, I am reminded that climbing Arnstein's ladder (1969/2007) truly is possible. -Donna Thompson, Professional staff, Australia

I am a BIPOC (Black, Indigenous, and People of Color) cisgender woman, and the Associate Dean of Teaching and Learning at Lafayette College, where I direct the Center for the Integration of Teaching, Learning and Scholarship. Forming partnerships with faculty members, students, and staff is critical to my center's mission. A post-COVID-19 era during a time of anti-Black racial unrest and diversifying student populations 
presents many opportunities for student-instructor partnerships focused on inclusive teaching, as learners are essential informants as to whether classrooms are equitable and welcoming. I continue to witness the mutual benefits of such relationships when instructors develop inclusive teaching plans, work closely with student partners to obtain observational and mid-course feedback, and refine their teaching practices. With the ever-changing teaching scenarios likely to come, understanding how to better build community in the classroom and how to confront systemic barriers by listening to student voices will be critical.

-Tracie Addy, administrator, Lafayette College, USA

We recently conducted a study in which a framework for structured training of small group facilitators was co-created through student-teacher partnership (Iqbal et al., 2020). We involved students as equal partners in the design process because their voices are usually ignored while designing faculty development programs. While reflecting upon their co-creation experiences, some teachers showed reservations toward meaningful student contribution in designing teacher training frameworks because students lack relevant teaching knowledge and experience. Although I acknowledge this limitation to a certain extent, I strongly advocate the active involvement of students as partners in designing faculty development programs as they are the direct beneficiaries of faculty development. It is, however, important to overcome this limitation to boost up the role of students as partners in the context of faculty development. I suggest that faculty sensitization, students' confidence building, and contextual training of both students and teachers prior to co-creation activity could help in overcoming this limitation.

-Muhammad Zafar Iqbal, Academic faculty/staff, Imam Abdulrahman Bin Faisal University, Saudi Arabia

Globally, several well-known universities are championing Students-as-Partners practice in pedagogical research projects. This movement of staff inviting students to actively participate in their educational development has seen hundreds of projects to enhance education. However, it is worthwhile considering that perhaps we only allow, or facilitate, such partnership working in "safe" project spaces, where staff still have the majority of control. Therefore, the riskier, and potentially more difficult, students-aspartners work, such as co-marking, co-teaching, and an ethos of partnership, need further attention to ensure our students are true partners across all aspects of Higher Education.

-Tom Lowe, administrator, University of Winchester, England 


\section{Breaking out of rigid structures and ways of being}

I (student of cultural studies) think that the coronavirus is showing us the connection between all countries and people across the globe. The crisis is guiding us into a future in which we are fighting against discrimination and injustice. In Donna Haraway's (1988) words: "We do need an earth-wide network of connections, including the ability partially to translate knowledges among very different-and power-differentiatedcommunities" (p. 187). SaP, as a collaboration of students, teachers, and scientific staff, could be the starting point, because this collaboration is a paradigmatic shift in thinking and acting: reflecting about power, hierarchies, and injustice is an essential part of it. All we need is a pause in which we have time to think about new possibilities, instead of staying in the hamster wheel of rigid structures and a hierarchical relationship between students and teachers.

-Marie-Teres Lewe, student and scientific assistant, University of Leipzig, Teaching Excellence Center/Hochschuldidaktisches Zentrum Sachsen, Germany

As Teaching and Research staff who straddles undergraduate/Research Higher Degree training and research in science and some in teaching, I have found that student-staff partnership (SSP) has enabled me mutual reflection on teaching and learning practice, co-learning and co-design, and connecting Indigenous students to curriculum design. SSP has improved our course-level teaching and highlighted the students' desire to boost the use of podcasts and EDx Edge (an online learning management platform). SSP has generated videography to profile employers and materials for Indigenous Knowledge in the Science curriculum. SSP students have taken on leadership roles and have engaged with staff and students beyond the SSP. I have greater appreciation of student learning preferences to more competently adjust content and delivery modes. In a nutshell-SSPs are very effective and enjoyable and generate far-reaching benefits. -Susanne Schmidt, Academic staff/faculty, Australia

As a recent graduate and a current intern within the higher education sector, I can see first-hand how the COVID-19 pandemic has fundamentally altered the way students are taught. If the pandemic has taught us anything it is that technology and digital aptitude are crucial. Appreciation of this, and the strong likelihood of a continuing transition towards a virtual learning environment, reveals key opportunities to increase representation, inclusivity, and diversity. By overthrowing the constraints of hierarchical learning (Monico \& Kupatadze, 2020) and associated intimidation, the online environment actively breaks down physical barriers and geographical obstacles, enhancing the participatory reach and inclusivity of education. This atmosphere facilitates collaborative discussions, constructive partnerships, and increased student agency. In this respect, the COVID-19 pandemic has encouraged us to reflect on traditional teaching and learning practices, providing the impetus for a transition to an 
environment of mutual respect, reciprocity and shared responsibility (Cook-Sather, Bovill, \& Felten, 2014).

-Holly Beth Rodgers, Graduate Intern of Curriculum 2025 Design, Coventry University, UK

As the Learning Technology Director for a large U.S. university system with full-time teaching experience at one of our campuses, I have a unique academic, technological, and administrative perspective on course development. Through research and engagement with a variety of campus stakeholders, it is well understood that adopting Open Educational Resources (OERs) decreases costs to students. Another, lesserdiscussed benefit of OER is the opportunity for "meaning making" via student/faculty co-creation activities. OER co-creation can be leveraged to address student diversity, equity, inclusion and belonging by improving access to course materials, as well as through student/faculty engagement in co-creating course content that is relevant to the student context. Customizing case studies and examples to reflect the experience, community, and perspective of students allows them to see themselves reflected in coursework. OER co-creation also provides a means to provide high-impact practices (HIPs) that deepen student engagement even further.

-Renee Pfeifer-Luckett, Administrator, University of Wisconsin System Administration, USA

\section{CROSSING DISCIPLINARY AND INSTITUTIONAL BOUNDARIES}

As a STEM (sciences, technology, engineering, and mathematics) major, I wonder.... Why are labs prescriptive? Why are classes lecture based? How do class structure and curriculum affect what knowledge and inclusion mean in STEM? As coordinator of Vassar College's pedagogical partnership program, I'm in awe of how interdisciplinary perspectives intersect, pedagogies diversify, and discussions open up when faculty in STEM partner with students from the humanities. I think the interdisciplinary exchange that pedagogical partnerships foster could develop classroom and college communities centered on collaboration over competition and create culturally relevant pedagogies to globally increase inclusion in STEM. The transition to remote and hybrid models has shaken up higher education to reveal an opportunity to visualise teaching as learning and learning as teaching. How can we create mediums for feedback and growth and affirmative spaces to contribute and feel valued? I'm excited to discover how teaching and learning blur to illuminate the value in all of us.

-Nandeeta Bala, student, Vassar College, USA

We often talk about students as partners within the academy but consider less the impact of partnership between students and external organisations. Students at the University of Manchester alone represent a 40,000-strong force for potential change. 
Using the United Nations Sustainable Development Goals as pedagogy, our University Living Lab aims to harness that force through partnership. We link students to applied research for sustainable development set by external organisations. The research projects could be adapted to any assessment at any learning level. Two students have been employed by organisations they did their research for and organisations are using student research to inform policy and practice. We are keen to share and grow this opportunity and would welcome extended partnership at any scale. Imagine the impact that we could have together.

-Jennifer O'Brien, academic faculty/staff, University of Manchester, UK

As an academic staff in Health/Biomedical Sciences, working at higher education institutions nationally and internationally for more than a decade, I foresee that in the next 3-5 years, students working as partners with local and global communities may work and develop alongside university staff in a variety of contexts to celebrate diversity and Indigenous perspectives/knowings and to build technology for delivery of future learning content. With COVID-19, students working as partners with university staff in the design and development of potential virtual space, collaborative online learning environments, and future opportunities for diverse students will be vital to ensure that learning is made available for all.

-Isabelle Lys, academic staff/faculty, Australian Catholic University, Australia

To maintain its innovative value, the future of students-as-partners projects must be suitable within international, cross-institutional, and multidisciplinary dimensions. The higher education sector will be instrumental in the efficiency, success, and sustainability of the post-pandemic recovery. With adequate investment, tertiary education can curtail globally growing social inequities and contribute to scientific breakthroughs and the development of a new knowledge economy. This advocacy can also extend to the defence of the humanities, arts, and social sciences, which are increasingly being diminished through emerging neo-liberal discourses. The attainment of a higher education qualification should not be viewed through a superficial, transactional, or elitist lens. It is time to transcend the stigma attached to different schools of thought. To be effective, this can only be achieved through a cultural transformation, at the intersection of universities, government, businesses, not-for-profits, and student activism. It must come from the top-down and bottom-up, across sectors and organisations' levels.

- Lisa Marie Lewis and Rose Lewis, students, Western Sydney University, Australia

WHAT DO WE WANT? More pedagogical partnerships between higher education institutions. WHEN DO WE WANT IT? In the next 3-5 years! Students-as-partners work has made huge strides in challenging the neoliberal assumption of the "student as consumer" within Higher Education. It's now time for us to surmount the power 
relationships that exist between universities in a competitive market and drive forward greater inter-institutional partnership work. Pedagogic collaboration between staff and students at different types of institutions offers hope for co-creating solutions to shared problems across the sector and learning together for the benefit of all.

-Karen Arm, Senior Lecturer in Learning and Teaching, Solent University, UK

As a long-standing, multidisciplinary, cross-institutional team, our research focuses on the mental wellbeing of post-secondary students. We have engaged in successful student partnerships over the last 5 years, with some partnerships lasting several years. While many students are interested in working with us, we are often limited to working with them on a volunteer or course-credit basis, since our informal team structure limits internal/external funding. Others wishing to partner with students (e.g., librarians, contract faculty, staff, postdoctoral fellows, educational developers) face similar challenges. Critically, this decreases the diversity in who is forming student partnerships. We propose a system of independent funding for merit-based research proposals by anyone, regardless of affiliation or status. As it is not uncommon for SoTL researchers to function outside the traditional frame of academic research structures, this system should facilitate cross-institutional and international matching of partners who have overlapping interests and varied backgrounds.

-Ayesha Khan, McMaster University; Heather Poole, University of Ottawa; Alyssa C. Smith, University of Waterloo; two teaching faculty and one graduate student, Canada

\section{CONCLUSION}

The contributions in this pilot version of Voices from the Field invite readers to explore the role of cross-cultural exchanges in enhancing partnership work and challenge readers to expand current conceptualizations of partnership work beyond Western understandings of partnership. They also raise questions about whose voices are included and whose voices are excluded and how we might expand who is considered a "typical" student partner to build a more inclusive literature and practice base. Contributions include questions of language and power in partnership, which affect whose voices are included and how to hear them. Getting behind-the-scenes glimpses at how research papers are constructed, bringing student perspectives to the research process, and positioning students as peer mentors in research can all inform more responsible approaches to, and outcomes of, research and afford students opportunities to imagine themselves as researchers. Contributions also identify the need for, and possible steps toward, an ethos of students-as-partners work-how to create a studentcentered ethos, what such work has achieved thus far, and where we might go moving forward to expand partnership work for greater inclusivity. Finally, they highlight the power of crossing boundaries - of disciplinary divisions, of institutions, of roles. Such crossing of boundaries makes space for celebrating diversity, Indigenous perspectives/knowings, and developing new forms and media for engagement. 
The voices included in this first voices-from-the-field section raise questions and possibilities that warrant further exploration. Possible future questions for this section include: Beyond questions of whose voices are included and excluded, whom do we not reach at all? Might we feature students-as-partners experiences through different media, such as videos that explain projects and concepts? What are the most significant contributions students-aspartners work has made to higher education over the last ten years? What does successful partnership mean to different people?

\section{COLLECTIVE REFERENCES}

Arnstein, R. S. (1969/2007). A ladder of citizen participation. Journal of the American Institute of Planners, 35(4), 216-224. https://doi.org/10.1080/01944366908977225

Bindra, G., Easwaran, K., Firasta, L., Hirsch, M., Kapoor, A., Sosnowski, A., Stec-Marksman, T., \& Vatansever, G. (2018). Increasing representation and equity in students as partners initiatives. International Journal for Students as Partners, 2(2), 10-15. https://doi.org/10.15173/ijsap.v2i2.3536

Chick, L. N. (2019, March 28). SoTL as public scholarship. Nancy L. Chick: Virtual office. https://nancychick.wordpress.com/2019/03/28/sotl-as-public-scholarship/

Cook-Sather, A., Bovill, C., \& Felten, P. (2014). Engaging students as partners in learning \& teaching: A guide for faculty. San Francisco: Jossey-Bass.

Haraway, D. (1988). Situated knowledges: The science question in feminism and the privilege of partial perspective. Feminist Studies, 14(3), 575-599. https://doi.org/10.2307/3178066

Iqbal, M. Z., Könings, K. D., Al-Eraky, M., AlSheikh, M. H., \& van Merrienboer, J. J. G. (2020). Development of an entrustable professional activities (EPAs) framework for small group facilitators through a participatory design approach. Medical Education Online, 25(1). https://doi.org/10.1080/10872981.2019.1694309

Kaur, A. (2020). Students as partners: Challenges and opportunities in the Asian context. International Journal for Students as Partners, 4(2), 145-149. https://doi.org/10.15173/ijsap.v4i2.4366

Liang, Y. \& Matthews, K. E. (2020). Students as partners practices and theorisations in Asia: A scoping review. Higher Education Research \& Development. https://doi.org/10.1080/07294360.2020.1773771

Nakata, M. (2007). The cultural interface. The Australian Journal of Indigenous Education, 36(S1), 7-14. https://doi.org/10.1017/S1326011100004646

Monico, C., \& Kupatadze, K. (2020). Developing meaningful and practical global experiences through student-faculty-community partnerships. International Journal for Students as Partners, 4(2), 9-26. https://doi.org/10.15173/ijsap.v4i2.4002 